\title{
Specification a Model for Study of Pro Environmental Behavior
}

\author{
Cruz García Lirios* \\ Academic Transdisciplinary Network, Mexico
}

*Corresponding Author: Cruz García Lirios, Academic Transdisciplinary Network, Mexico

\begin{abstract}
Under the Sustainable Development of the incorporation of different worldviews, the present work is to expose the vicissitudes avocet preventing sustainability models incorporate symbols, meanings and senses of community and sustainability oriented organizations once economic instability and environmental crisis threatening its existence. For this purpose, the written part of the assumption that preserving natural resources for future generations is delineated by models that overcome the dilemma of economic growth or economic development. Discussion of local development issues in reference to the global growth of transnational integration in communities with respect to the internationalization of SMEs will understand the future of human needs based on resource availability.
\end{abstract}

Keywords: Growth, development, organizations, communities, calendar

\section{INTRODUCTION}

The community, organizational and sustainable development, have often been considered opposites both models posed development from economic growth, industrial production and exploitation of nature as from those models proposed development from liberalization at least ethics, humanity in reference to consumerism. In such a scenario, communities and organizations are assumed as barriers to economic growth or eco-development. In this sense, the purpose of writing this is to review the fundamentals of sustainability models to discuss the emergence of an integrated model in which communities and organizations are incorporated into the construction of a global environmental agenda symbols, meanings and senses aimed at establishing new relationships between humanity and nature.

However, this letter of the assumption that organizations and communities can be incorporated in the proposals for sustainability if they consider their values, norms, beliefs, knowledge and innovation as fundamental to development, however such dimensions that run traverses it would expose and then infer the asymmetries between organizations and communities in the context of financial globalization and Sustainable Development.

The work assumes that diversity factors affecting the sustainability of natural resources, if only limited to expose those barriers to mankind developed steadily from emergency civil organizations and business communities. It is at the convergence of SMEs and multinationals where you can discuss sustainability models that could incorporate community values and organizational production. This is because globalization is indicated by the internationalization of SMEs and multinationals inserting the local market, in both processes, strategic alliances result in the coexistence of community traditions and organizational cultures.

However, models of sustainability avocados to the management of knowledge and values that respect nature start from the fact that relations between communities and organizations are asymmetric as the first approach to consider natural resources as part of the history of peoples lie that organizations use nature as a means to achieve its goal of internationalization or joining the local market. These assumptions have led to models of sustainability manage economic growth and ecological development without considering the future of communities and organizations.

Therefore, it is essential to discuss the implications of the principles of sustainability models to envision building a sustainability agenda in their local and global dimensions. 


\section{THEORY OF PROENVIRONMENTAL BEHAVIOR}

Discursivist ethical and eco-economist's developmental models, ethical environmentalist, bio-centric, territorialism, communitarian, regionalist, presionist and eco-tourism have emerged as proposals to local environmental issues and sustainable endogenous development. Such models assume that in a situation of vulnerability, as indicated by its availability of natural resources and quality of public services, the capacity of communities and neighborhoods are threatened by reducing opportunities, although given the increased responsibilities, is may contribute to risk reduction, energy optimization, improved productivity, promotion of health and prevention of environmental crime.

Local sustainability models underlying diagnosis of community or neighborhood capabilities in conflict with the availability of natural resources. Include the establishment of relations between modifiable constructed and intangibles from land use and urban planning (López y López, 2012) spaces. In this process, the participation of communities, neighborhoods, organizations or boundaries is critical as building a local agenda to guide the decisions and collective actions (Mori, 2008).

However, models of sustainability can also be implemented in organizations dedicated to ecotourism or organic production as their main purpose is to adjust the guidelines of Sustainable Development to the social responsibility of businesses and business guide to preserving the environment cultures promoting recycling and reuse styles in addition to being a field of values, norms and beliefs organizations are driving job and nature friendly products and resources that serve as inputs or the quality of life and wellbeing staff are incentives for companies care about their customers by offering them quality indicated compliance with international standards (Ortiz and Camargo, 2010).

However, each of the models assumed humanity as a separate entity from the laws of nature, forms of coexistence and interdependence. Intervention models for sustainability assume that the solution to the ecological problem is human rationality and emotion rather than climate processes. Even assuming humanity as an agent of conflict and change that nature should adjust its resources to achieve preserve itself and thereby ensure the vulnerability, marginalization or exclusion of communities and suburban neighborhoods (Aznar, 2002).

In this process of diagnosis, intervention and evaluation, Institutions and Universities of Higher Education (IUES) are called to make a commitment to manage; produce or reproduce, translate or dismember knowledge concerning the state that keep the natural resources in reference to the socioeconomic projection of current and future generations (González, 2013).

The university, while local growth factor, is coupled to the eco-tourists are assumed as an alternative to economic growth pours currency and employment generation projects. The models focused on water tourism, extreme, beach or mountain pose the lifestyles linked to risk are a "safety valve" for urban living and customer satisfaction will become a series of visits to the beautiful places or magic which not only make it more exciting and significant thus the lives of those who have the purchasing power to such activities but also grant value to tourist sites triggering a "domino effect" in which visitors and walkers will demand services localities or areas for recreation, fun and entertainment (Rojas and Hansen, 2006).

The local immersed development in the eco-tourism seems to depend on a chain of trust, satisfaction and comfort rather than investment in industrial, job creation and job placement after training programs and training local residents. In this sense, the process from the global to the local dependent on external rather than internal factors, banks are just mere intermediaries for the transfer of currency and conversion of nature resources, goods, services or consumer products seems I assumed as part of the model eco-tourist, however its consequences are considered as external or as much collateral development.

In parallel, regionalist and presionist models consider the imbalance between resources and population as a factor affecting the socio-economic development and its impact on natural capital and biodiversity. Unlike presionist, regionalist includes community participation while presionist only takes into account the population, production and consumption projections to establish dependency relationships between the use of energy and the agreements or arrangements between local authorities (Torres Rodriguez and Sanchez, 2004).

There are two dissimilar models, but derivatives assumption that between global and local development, regions act as intermediaries; regulate and moderate the extractive, transformative and distributive processes in which natural resources are involved depending on the needs and 
expectations of current generations without considering the opportunities for resource management and generation of knowledge for the development of future generations. Often, the diagnosis of the availability of natural resources and prognosis of exhaustion served in endogenous development planning in reference to the regional situation.

In contrast to presionist and regionalist models, the territorialist emerging opportunities, abilities and responsibilities that the market offers communities and neighborhoods. The demarcation of the territory of production, distribution and consumption is a result of foreign investment and the transfer of knowledge and technology. The local is reduced to a passive expression versus mobility market through supply and demand for products and services. Natural resources are only an instrument of development while the actors of global production chains are the same at regional and local level. Partnerships between SMEs and multinationals are assumed to be strategic in both create jobs, but partnerships with other actors are not understood as pillars of development and that cooperation agreements between SMEs and multinationals cover labor supply and of demand for jobs (Sánchez and Moreno, 2010).

That is, growth according to says the economist model is the result of a continuous process of technological innovation, full employment and equitable distribution of resources, even if it means a gap between developed and developing countries (emerging economies), communities and organizations are only assumed as instruments for endogenous development in reference to the global market. By contrast, the eco-development model proposed consensus among stakeholders to establish a common agenda to the interests of majorities and minorities taking into account the availability of resources and environmental threats and industrial threaten the stability of localities, regions or global systems (Urteaga, 2011).

At another extreme, bio-centric, ethical and ethical-ecological discursivist communitarian models assume that the imbalance is a shared responsibility between the actors and that about building a sustainable agenda, vulnerable, marginalized and excluded can bring knowledge whose discussion is essential for public debate, public safety and social peace.

The communitarian model emphasizes the participation of indigenous peoples and neighborhoods from which is to understand nature as a local identity element rather than development. Thus, residents of outlying areas are those who defend their right to the city and natural resources and the demand for public services relating to the availability of public and common goods. This is where the bio-centered model favors the conservation of animal and plant species at the expense of human needs. From this approach, natural resources are part of a system in which humanity is a species and therefore the ecological footprint that threatens its continuity is observed as a phase of changes that nature experiences and which species are or become extinct.

However, preservation uncompromising nature is seen from the ethical discourse model as an irrational result derived from a confused reflection relationships between nature and humanity saved. The scientific community would be closer to this model of sustainability since nature is perceived as an object of study, modifiable from urban planning. In contrast, the ethical-ecological model holds that communities and organizations are just part of the natural resources and as moral entities are likely to be released at least from their values, beliefs and norms as far as production and consumption is concerned.

In short, sustainability models are prone to conflict and change as they start from a dissonant relationship between nature and humanity, whether by their values, beliefs and norms or their structures, systems, tools and results, the models pose opportunities capabilities and responsibilities that present generations should take to the delight of future generations.

\section{CONCLUSION}

Under the Sustainable Development organizations and communities seem to be reunited in the process of internationalization of SMEs and the entry of multinationals to the local market, however, insist sustainability models consider the development of communities and organizations passes through different paths. In principle, models of sustainability oriented exclusive development for present generations believe communities are a symptom of emerging economies as they are, as stated in the economic developmental logic, transition towards full employment. For its part, the eco-development models argue that organizations are lacking entities of values, norms and beliefs from which one can infer a biased culture to gain and hence unfavorable environment. In both models, economist and eco- 
developmental, communities and organizations primarily in second, are barriers to sustainability, but perhaps the essential problem is that both models assume that organizations and communities are opposed. In this context, it is essential to discuss the relationships that keep communities and organizations in reference to the guidelines of sustainable development and financial-economic globalization.

Organizations, unlike communities are confined to technological innovations because they are his instrument to adjust their production to the logic of global and local markets. In contrast, communities are entities of uses and customs in which the symbols, meanings and senses determine traditions, myths, values, norms and beliefs that approach the care of natural resources while organizations, including those socially responsible, assume that nature is a supplier of inputs and in any case receiving waste. Such relationships between communities and organizations with respect to natural resources seem to show that both are opposite, however, in situations of scarcity, risk and uncertainty, communities have shown that trust, solidarity and cooperation are more than just symptoms capital or support networks are in essence symbols, meanings and senses sustainability organizations that present themselves when establishing partnerships with a financial crisis, financial recession or economic slowdown.

For the training of human capital, values, beliefs and traditions of the communities converge with the knowledge and skills of organizations. If universities to community and organizational can coexist, then in models of sustainability symbols, meanings and feelings of trust, solidarity, respect, cooperation and innovation can be compatible for the construction of a public agenda for sustainable development.

However, the convergence of community organizational principles is not an easy task since the extinction of natural resources has affected the differences between communities and organizations to such an extent that now the native peoples strongly defend their rights resources and organizations in their quest to survive established chain networks in which state deregulation allows the excessive exploitation of nature.

That is why sustainability models should not only include the Community and organizational but also should move towards legal regulation schemes where environmental protection is an indicator of development that can be supplemented with civil participation. As the legal framework protects the availability of resources for future generations, building a sustainable agenda should be discussed in the civil, political, economic, academic, community and organizational spheres. Such an exercise will distinguish our civilization as one in which climate change opened the opportunity to build symbols, meanings and senses of sustainability.

\section{REFERENCES}

[1] González, Ariel. (2013). La universidad como factor de desarrollo local sustentable. Ra Ximhai, 9, 65-78

[2] López, Adriana y López, Oswaldo. (2012). Conceptualización de un modelo de intervención urbana sostenible. Ecobarrios en el contexto latinoamericano de reciente creación. Revista de Arquitectura de la Universidad de Católica de Colombia, 14, 116-127

[3] Ortiz, Fidel y Camargo, Isis. (2010). Propuesta de valores para una cultura organizacional en el desarrollo sostenible. Revista de Turismo y Patrimonio Cultural, 8, 125-138

[4] Sánchez, Celia y Moreno, Antonio. (2010). Mercados de trabajo locales y desarrollo territorial sostenible. Revista de Trabajo de la Universidad de Huelva, 23, 115-134

[5] Urteaga, Eguzky. (2011). Las teorías alternativas del desarrollo sostenible. Boletín de la Asociación de Geógrafos Españoles, 55, 113-126

Citation: Cruz García Lirios. "Specification a Model for Study of Pro Environmental Behavior". International Journal of Research in Tourism and Hospitality (IJRTH), vol 5, no. 4, 2019, pp. 15-18. doi: http://dx.doi.org/10.20431/2455-0043.0504004.

Copyright: () 2019 Authors. This is an open-access article distributed under the terms of the Creative Commons Attribution License, which permits unrestricted use, distribution, and reproduction in any medium, provided the original author and source are credited. 